\title{
La fabricación de una comunidad moral. El caso de los afectados de la causa Matanza-Riachuelo
}

María Carman. Universidad de Buenos Aires, Buenos Aires, Argentina.

RESUMEN | A partir de una etnografía desarrollada entre 2010 y 2015, analizaré la relocalización de villas ribereńas de la ciudad de Buenos Aires ordenada por la máxima autoridad judicial argentina, debido a su cercanía a un río altamente contaminado. He de indagar de qué modo algunos habitantes de un entorno problemático apelan a una narrativa ambiental que suele sumarse a un eje reivindicativo en torno a la vivienda o las condiciones de vida. ¿Cómo puede articularse el derecho a un ambiente sano -que puede quedar anclado en un mero reconocimiento cultural de "ser afectados"- a una red dinámica de otros derechos? El mal que aqueja a algunos de esos cuerpos deviene, mediante diversas traducciones, reclamo político. El análisis de las negociaciones de los afectados nos remite al potencial del sufrimiento en la creación de comunidades morales (Pita, 2010) y en la búsqueda de reconocimiento para torcer el rumbo de ciertas políticas.

PALABRAS CLAVE | gestión ambiental, desigualdad social, política habitacional.

ABSTRACT | Based on an ethnography study conducted between 2010 and 2015, I analyze the relocalization of riverside slums in the City of Buenos Aires. Argentina's maximum judicial authority mandated the process due to the neighborhood's proximity to a highly contaminated river. I investigate how some dwellers of a problematic location appeal to an environmental narrative, which typically adheres to a core claim regarding housing or living conditions. How can the right to a healthy environment -which can be anchored on the mere cultural recognition of "being affected"-articulate with a dynamic network of other rights? The harm, which afflicts some of those bodies, becomes, through diverse translations, a political device. The analysis of the negotiations of those affected brings us to the potential of suffering in the creation of moral communities (Pita, 2010) and in the search for recognition in order to bend the path of certain policies.

KEYWORDS | environmental management, social inequality, housing policy.

Recibido el 19 de marzo de 2018, aprobado el 1 de octubre de 2018 .

E-mail: mariacarman1971@gmail.com 


\section{Introducción}

El presente trabajo analiza el proceso de relocalización de villas ribereńas de la ciudad de Buenos Aires ordenado por la máxima autoridad judicial argentina debido a la cercanía de dichos asentamientos al Riachuelo, un río altamente contaminado. He de indagar de qué modo algunos habitantes de un entorno problemático apelan a una narrativa ambiental, que suele sumarse a un eje reivindicativo en torno a la vivienda, el territorio o las condiciones generales de vida. En la coyuntura de la relocalización, el problema no es tanto la negación explícita de derechos, sino la concesión de derechos que soslayan, opacan o excluyen otros.

¿Cómo puede articularse el derecho de esa población a un ambiente sano -que puede quedar anclado en un mero reconocimiento cultural de ser afectados- a una red dinámica de otros derechos? El mal que aqueja a algunos de esos cuerpos en su intimidad deviene, mediante diversas traducciones, reclamo político. El análisis de las disputas y negociaciones que encaran los afectados de la cuenca nos remite al potencial del sufrimiento no solo en la creación de comunidades morales (Pita, 2010, p. 196), sino en la búsqueda de reconocimiento para torcer el rumbo de ciertas políticas públicas.

\section{Metodología}

Para llevar adelante la investigación opté por un abordaje cualitativo, de corte etnográfico. Desarrollé un trabajo de campo exhaustivo entre los años 2010 y 2015 en las villas porteńas ribereñas afectadas por el proceso de relocalización ordenado por la Corte Suprema de Justicia Argentina; en particular, en la villa 21-24 del barrio de Barracas.

He realizado entrevistas abiertas y en profundidad con los siguientes actores: funcionarios y empleados de la Defensoría General de la Ciudad, del Instituto de la Vivienda de la Ciudad, de la Autoridad de la Cuenca Matanza Riachuelo (ACUMAR), de la Defensoría del Pueblo de la Ciudad y de la Asesoría Tutelar de Menores de la Justicia porteńa; representantes de diversas ONG; vecinos afectados o ya desplazados de la villa 21-24, y de los asentamientos de la calle Romero (Pompeya), Luján y Magaldi (Barracas). Participé en reuniones de delegados del camino de sirga de la villa 21-24; en desayunos de trabajo en el Instituto de Vivienda; en audiencias públicas en la Corte Suprema; así como en reuniones, asambleas y censos en los nuevos Complejos Habitacionales de Castańares / Portela /Lafuente y Padre Mugica. También he realizado un seguimiento de fuentes secundarias a propósito del Plan de Urbanización de Villas y Asentamientos Precarios en Riesgo Ambiental Cuenca Matanza Riachuelo, que incluyen Informes de la Defensoría General de la Ciudad, de la Defensoría del Pueblo, del Ministerio Público Tutelar de la Justicia Porteña y de diversas dependencias del Gobierno de la Ciudad de Buenos Aires. Junto con lo anterior, he revisado estadísticas, audiencias y resoluciones judiciales, materiales de páginas web, y medios de comunicación barriales y nacionales. 


\section{El hito jurídico}

La cuenca hídrica de los ríos Matanza y Riachuelo, cuya superficie ronda los $2.240 \mathrm{~km}^{2}$, atraviesa la provincia de Buenos Aires y vierte sus aguas en el Río de la Plata, a la altura del barrio de La Boca, luego de recorrer $80 \mathrm{~km}$. El ciudadano porteńo promedio no ha visto más que su desembocadura en La Boca, una zona turística por excelencia, aunque puede deducir el resto sin esfuerzo: un río extenso en cuyas orillas conviven industrias y villas; un río fétido, símbolo de la contaminación, que provoca sufrimiento ambiental a los habitantes populares próximos. ${ }^{1}$ Mucho más difícil es imaginar, en cambio, cómo era aquel paisaje sin las aguas renegridas, burbujeantes y espesas; sin su olor penetrante y nauseabundo.

Como señala Silvestri (2003, p. 23), el Riachuelo siempre tuvo un rol relevante en el destino de Buenos Aires por su triple condición de puerto natural, área de concentración productiva y límite político de la ciudad. Se trata de una vasta superficie dividida en una cuenca alta -en la cual predomina un paisaje rural-; una cuenca media, en la que ya es posible vislumbrar industrias y viviendas de una zona periurbana; y por último, el consabido escenario de fábricas, industrias, asentamientos urbanos y esporádicos basurales característico de la zona altamente urbanizada de la cuenca baja.

En 2004, una psicóloga social que se desempeñaba en Villa Inflamable inició, junto a 16 vecinos y profesionales de la salud del partido de Avellaneda y el barrio de La Boca, una demanda ante la Corte Suprema de Justicia contra los gobiernos nacional, bonaerense y porteńo en reclamo por dańo ambiental colectivo. Beatriz Mendoza -tal su nombre- y el resto de los vecinos acusaban a 44 empresas de no construir plantas de tratamiento y de volcar residuos peligrosos al río. En la búsqueda de que sus penurias fueran transformadas en un hecho legal, los vecinos sumaron sus historias clínicas para reclamar por daño ambiental colectivo.

En 2006, la Corte dividió el reclamo de los vecinos en varios expedientes: declaró su competencia respecto del daño colectivo, y difirió la resolución sobre los daños individuales, morales y psíquicos. Aquel primer año estuvo signado por una andanada de extraordinarias innovaciones en el abordaje judicial de la cuestión ambiental. En la búsqueda de mostrar un rostro más humano y los profundos cambios de ese tribunal, comenzaron las primeras audiencias públicas y se creó un primer comité de cuenca interjurisdiccional: la Corte intimó a los gobiernos a presentar un plan de saneamiento y a las empresas a tomar medidas para revertir la contaminación.

Asimismo, la Corte dispuso la creación de la Autoridad de la Cuenca Matanza Riachuelo (ACUMAR), un ente tripartito compuesto por representantes de la Nación, la provincia de Buenos Aires y la Ciudad Autónoma de Buenos Aires, cuya misión es llevar adelante el Plan Integral de Saneamiento Ambiental (PISA) definido por expertos de esos tres ámbitos del Estado, y que incluye obras de infraestructura, limpieza y mantenimiento del espacio público; control de las condiciones ambientales y de la actividad industrial; y la relocalización de las villas que se encuentran

1 Se estimaba que unas 500.000 personas vivían en villas y barrios informales de la Cuenca Matanza-Riachuelo (Merlinsky, 2013, p. 74) en los ańos previos a las relocalizaciones. 
sobre los márgenes. Los objetivos apuntan a mejorar la calidad de vida de los habitantes de la cuenca; recomponer el ambiente en todos sus componentes -agua, aire y suelos- y prevenir dańos futuros.

La justicia conminó al Ejecutivo, pues, a transformar la omisión en acción. Ante la pasividad de los demás poderes en esta vulneración de derechos, el Poder Judicial asumió una estrategia de exigibilidad de las medidas de reparación necesarias de adoptar, con el objeto de que la resolución del caso legal contribuyera a transformar las deficiencias institucionales (Abramovich, 2007).

En el año 2007, la ejecución de la causa Mendoza fue delegada por la Corte Suprema en Armella, juez federal de Quilmes, quien desempeńó un papel clave en la "reinvención" de la categoría del camino de $\operatorname{sirga}^{2}$ y la delimitación de las líneas de acción respecto de los afectados.

Finalmente, la Corte ordenó la conformación de un Cuerpo Colegiado para el control ciudadano del Plan de Saneamiento, conformado por el Defensor del Pueblo de la Nación y cinco ong que representaban el interés público ad honorem: la Fundación Ambiente y Recursos Naturales, el Centro de Estudios Legales y Sociales, la Asociación de Vecinos La Boca, la Fundación Greenpeace y la Asociación Ciudadana por los Derechos Humanos.

A partir del emblemático fallo Mendoza del año 2008, la Corte Suprema de Justicia de la Nación instauró un set de responsabilidades ambientales: dispuso líneas de acción y ordenamiento territorial para la refuncionalización de la cuenca; y definió los municipios participantes y el plazo en que las obras debían ser ejecutadas, con la posibilidad de imponer multas en caso de incumplimiento. Tales líneas de acción incluían estudios sobre el impacto ambiental de las empresas demandadas, y la elaboración de un plan sanitario de emergencia y de un programa de educación ambiental.

La Corte ponderó, en suma, una determinada percepción del peligro que corría la cuenca y su población en caso de no tomarse urgentes medidas correctivas. Si, como afirma Merlinsky (2013, pp. 36-37), los conflictos ambientales a lo largo y ancho del país - movimientos en contra de la minería, demandas de pueblos fumigados o afectados por la instalación cercana de plantas de celulosa- son los que mayormente generaron las condiciones para la construcción de un ámbito público de deliberación sobre la cuestión ambiental, el conflicto del Riachuelo no hizo sino consolidar ese trayecto, transformándose en "un parteaguas que habilita un proceso [...] de institucionalización de la política ambiental en la Argentina”. En efecto, el fallo Mendoza está imbuido de una renovada impregnación ética (Habermas, 1999, p. 216) que coincide con la creciente conciencia experimentada por los ciudadanos en torno a su derecho a vivir en un ambiente sano. En consonancia con esa conciencia ambiental internalizada por la población, la defensa del propio territorio ha ido dando forma a las luchas socioambientales de las asambleas ciudadanas a partir del año 2001 en diversas zonas del país, cuyo reclamo se dirige tanto hacia grandes empresas transnacionales como hacia diversas instancias del Estado (Svampa, 2012, pp. 68-69). 
En las próximas páginas no he de reconstruir, sin embargo, la problemática entera del affaire de la causa Mendoza, ni la gestión de esta cuenca en contraste con otras cuencas hídricas, ni la desactivación de industrias contaminantes o el derrotero de los conflictos ambientales en la Argentina, temáticas ya abordadas por competentes colegas. Solo voy a ocuparme de un fragmento -si se quiere, menorde esta megacausa ambiental: el costo humano del saneamiento.

El recorte es aún más modesto, pues de un vasto universo de afectados de ambas orillas del Riachuelo, privilegiaré el caso de algunas villas porteñas. ¿Cómo se va transformando la vida de estos habitantes cuya presencia impide la construcción del camino de sirga y, al mismo tiempo, son beneficiarios de derechos ambientales?

El colectivo de los afectados está compuesto por personas que comparten su cercanía espacial al Riachuelo y el modo en que sus cuerpos son apreciados en relación con sus padecimientos ambientales, lo cual justifica la urgencia del traslado.

Antes de continuar el relato, vale una aclaración: resulta al menos paradójico delimitar un número acotado de beneficiarios ambientales de nuevas viviendas en el contexto más amplio de cientos de miles de personas que habitan viviendas sumamente precarias en el Área Metropolitana de Buenos Aires. Ese "conjunto escondido" con relación al cual se define el grupo instituido (Bourdieu, 1985, p. 79) aporta una clave de comprensión de esta política de relocalización. Tener derecho a una nueva vivienda en medio de un masivo e irresuelto déficit habitacional convierte a los afectados, al menos en teoría, en privilegiados.

\title{
Conviértete en lo que eres
}

\author{
“Conviértete en lo que eres". Tal es la fórmula contenida en la magia \\ performativa de todos los actos de institución. (Bourdieu, 1985, p. 82)
}

Como mencionamos antes, el juez federal de Quilmes Armella tuvo a su cargo la ejecución de la causa desde 2008 hasta fines de 2012. Su rol resulta clave en las problemáticas abordadas aquí, ya que es él quien jerarquiza la problemática de las villas circundantes, incorpora la cuestión de la liberación del camino de sirga y transforma esta cuestión -según el irónico comentario de una funcionaria- en su "caballito de batalla". El camino de sirga es una antigua categoría del Código Civil que el juez retoma para establecer la obligación de liberar 35 metros desde el talud del río, con el objeto de avanzar en la limpieza de las orillas y del curso de agua. Las sucesivas resoluciones redactadas por el juez definen el nuevo estatus de ese camino, destacando su recuperación, parquización, utilidad pública e interés ambiental.

En el ámbito de la ciudad de Buenos Aires, la liberación del camino de sirga se organizó en torno a un dégradé de casos. Primero fueron desalojados, sin ninguna vivienda a cambio, los habitantes de los asentamientos dispersos y precarios. Posteriormente, el operativo se centró en aquellas villas de un tamańo intermedio y variable nivel organizativo (Villa Luján, El Pueblito y Magaldi), cuyos pobladores fueron relocalizados con una suma de deficiencias. Finalmente, se relegó para una última etapa la relocalización de los habitantes de la sirga de la Villa 26 y la 
Villa 21-24, que ascienden a unas 1.334 familias y cuya organización se encuentra más consolidada.

La principal característica de los primeros desalojos motorizados por el Gobierno de la Ciudad a través de su Instituto de la Vivienda es que no tuvieron -pese a lo que indicaba el fallo de la Corte- una contrapartida habitacional y que comenzaron, no azarosamente, con los individuos o familias más desafiliados, sin capacidad organizativa ni poder de réplica. Las consecuencias del desarraigo se vieron agravadas porque estos primeros destinatarios de la manda judicial no contaban con la información de que debían dejar sus viviendas, o bien se enteraron del operativo con apenas algunos días de antelación. Varias de estas familias terminaron viviendo a la intemperie o en condiciones habitacionales peores que las de su anterior vivienda.

Los organismos defensores denunciaron oportunamente el caso emblemático de los Juanes, dos hombres que vivían desde hacía 22 ańos en una casa cedida por Prefectura en el barrio de La Boca y que ganaban alrededor de 20 pesos al día. Uno de los Juanes sufría ataques de epilepsia y no se realizaba controles desde hacía meses. A pesar de la intermediación de un organismo tutelar, el juez dispuso el desalojo compulsivo y la casa fue derribada. El Gobierno de la Ciudad no les brindó ningún seguimiento ni asistencia terapéutica y, luego de un par de días en un hotel, fueron a vivir a los peldaños de una escalera, en el mismo sitio donde antes había estado su vivienda.

Además de los Juanes, hubo al menos 17 casos de habitantes de ocultas villas ribereñas de la ciudad que fueron desalojados sin que les fuera asignada una vivienda. En los casos más extremos hubo una orden de allanamiento penal a personas indeterminadas y uso de la fuerza pública; las pertenencias de los expulsados fueron destruidas.

Soy uno de los primeros damnificados. [...] Vinieron con un papel que en veinte días teníamos que irnos, pero al día siguiente vinieron con las dos topadoras. [...] Entraron cincuenta policías con esos chalecos, y me obligaron a sacar todas mis cosas a la intemperie. "Te tiramos tu casa con tu hija y todo adentro", me dijeron. [...] Un poco más poniendo la pistola en la cabeza [...] Yo no me iba, no me quería ir y tenía veinte policías alrededor [...]. Parecía que fuésemos delincuentes... Tiraron dos casas para hacer el caminito ese [...] . Le obligaron a mi suegro y mi cuñada a firmar en el acta que nos habían reubicado [...], Nos quedamos acá [en la calle] con las cosas. Al día siguiente llovió y perdí de todo. (Entrevista a Eliseo de la calle Romero, barrio de Barracas, 2011)

El testimonio da cuenta del cinismo de la operatoria: el hecho de admitirlos como afectados no trae aparejado un set de políticas de dignidad. Antes bien, las personas son cosificadas, reducidas a un mero cuerpo -enfermo o vulnerable, eso sí- que ha de ser arrojado sin más a la intemperie.

Desde la perspectiva de los ejecutores de esta limpieza del camino, ¿por qué otorgar un derecho a personas sobre las cuales recae una sospecha de ilegalidad? Pareciera que los afectados más vulnerables no tuvieran, bajo esta interpretación, un estatus moral suficiente para acceder a sus derechos, o bien para ser escuchados. Un párroco de Barracas sintetizó el trato dispensado a estos primeros afectados del 
siguiente modo: "se sienten muy avasallados... se sienten tratados como parte de la basura”.

En similares condiciones de desinformación, negligencia y plazos perentorios, afectados de las villas de tamaño intermedio de la cuenca baja de la ciudad de Buenos Aires fueron mudados durante 2011 a complejos habitacionales de la zona sur de la ciudad, en los cuales los problemas para llevar adelante la vida no hicieron sino acumularse: falta de suministro de agua, gas, o electricidad; baja tensión y quema de artefactos; entrega precaria, sin mensura en propiedad horizontal; ausencia de cerraduras e iluminación general; proliferación de ratas, cucarachas y pulgas; ausencia de matafuegos e irregularidades en materia de seguridad frente a un eventual incendio.

La producción de vulnerabilidad de los primeros afectados porteńos de la cuenca fue cuestionada por la Defensoría del Pueblo de la Ciudad de Buenos Aires, la Asesoría Tutelar de Cámara y la Defensoría General de la Ciudad. Frente a reiterados reclamos de estos organismos defensores para evitar la situación de calle de los damnificados, el juez federal desestimó sus presentaciones alegando que estos no formaban parte del Cuerpo Colegiado consagrado por la Corte Suprema. Un abogado de uno de estos organismos defensores nos detalla esta tensión permanente con el juez federal:

Tuvimos reuniones en el Juzgado. Él dice que somos un obstáculo para la resolución de la causa. [...] Fuimos acusados por defender "derechos no vulnerados" [...]. Y eran vulnerables de toda vulnerabilidad: pobres, enfermos. [...] Saben que sos el enemigo, un organismo que impide que las cosas se hagan todo lo rápido que ellos quieren. [...] La última visita ocular [del juez Armella] fue en auto por la sirga y ni pasó por las villas. La gente lo estaba esperando...

La situación de los afectados se vio perjudicada por partida doble, pues ni la Defensoría del Pueblo de la Nación ni las ONG que sí tienen el privilegio de formar parte del Cuerpo Colegiado de la causa Matanza-Riachuelo cuentan con un trabajo territorial en las villas, con lo cual su incidencia en atenuar las arbitrariedades de las relocalizaciones resultó nula.

Los organismos defensores procuraron imponer, sin éxito, tiempos más laxos que minimizaran los impactos negativos de esas abruptas expulsiones. La búsqueda de un freno al ritmo del cambio equivalía aquí a atenuar la desafiliación de esos sectores. Asimismo, estos organismos defensores insistieron en su misión de controlar el desempeño de las instituciones ejecutoras (Instituto de Vivienda del Gobierno de la Ciudad y ACUMAR); erigirse como mediadores de los afectados ya relocalizados o por relocalizar; y sistematizar las penurias y demandas de estos últimos, canalizándolas a los organismos responsables de la ejecución de la causa. Uno de los habitantes desplazados sintetiza este asunto en su reflexión: "se frenó esto [las expulsiones sin relocalización] porque vino gente como ustedes para que no fuera tan violento".

A pesar de la escasa receptividad del juzgado federal interviniente y de las fallas en la supervisión de la política de realojo, la denuncia de estas expulsiones por parte de los organismos defensores llegó hasta los oídos de los jueces de la Corte Suprema. En una de las audiencias públicas regularmente fijadas por el máximo tribunal de justicia para que los distintos actores institucionales presenten los avances del 
saneamiento, la entonces ministra de la Corte Carmen Argibay increpó a un funcionario preguntándole si efectivamente estaban trasladando a los habitantes ribereños "como si fueran muebles". ${ }^{3}$

Antes de analizar el próximo caso, quiero subrayar una cuestión: no existe una política ecuánime de relocalización para todos los habitantes porteños de la sirga, sino una pragmática jerarquización de los afectados en virtud de su capacidad de movilización y sus competencias culturales y políticas. La política institucional de los organismos ejecutores varió considerablemente según cómo fueron apreciados los capitales de los afectados: su afiliación social, su participación en ciertas redes, o bien su relativo aislamiento.

\section{Exhibir el cuerpo doliente: la manipulación de los rangos de humanidad}

Vimos que la liberación del camino de sirga en la ciudad de Buenos Aires se estructura en torno a un dégradé de casos: primero, la expulsión de los habitantes más precarios; luego, las relocalizaciones deficitarias de villas de variable tamaño y organización interna, que fueron abordadas en otro trabajo (Carman, 2017); por último, la Villa 26 y la Villa 21-24. Esta última es conocida como la villa más grande de la ciudad: unos 70.000 habitantes que ocupan 60 hectáreas rellenadas con basura y escombros, y cuya historia de ocupación se remonta a la década de los cuarenta.

De las aproximadamente 55.000 familias que habitan la villa, solo 1.334 debían ser mudadas por vivir a menos de 35 metros del Riachuelo. Vimos que existe una producción del cuerpo enfermo en el perímetro acotado que fija los 35 metros: allí intervienen los dispositivos estatales para "devolver la salud" a los afectados. Fuera de esa traza, la integridad física de los vecinos de esta villa de 70.000 habitantes se verá descuidada una y otra vez por parte de ese Estado local. Aquí se suman muertes evitables por cables en mal estado, el paso del tren o la desidia policial. Al mismo tiempo en que se recorta una pequeña fracción de esas poblaciones para ser $-\mathrm{al}$ menos declarativamente- intervenidas y protegidas, una política de perpetuación de la precariedad y de desprotección de la vida sigue operando en la urdimbre de todos los días. La afección ambiental de aquellos que viven a más de 35 metros del Riachuelo seguirá siendo un problema del ámbito privado y, como tal, librado a la responsabilidad individual y familiar.

En medio de la consolidada apatía del Poder Ejecutivo porteńo hacia las condiciones de vida y hábitat de los más pobres, la intervención requerida hacia un mínimo conjunto de esos sectores populares con déficit habitacional no hizo sino reactualizar la crónica desconfianza hacia las actuaciones del Gobierno de la Ciudad.

A contrapelo de la visión oficial que da por descontado que la relocalización equivale a una instantánea mejora de las condiciones de vida, el trabajo de campo nos muestra que no todos los afectados aspiran a mudarse o viven su nuevo destino como un ascenso social. 
Tengo dos versiones: por cómo vivía la gente antes -como si fuese la gente del meandro, ${ }^{4}$ por ejemplo-, ahí están como en Las Cañitas. ${ }^{5}$ Para los que vivimos un poco mejor, [la nueva vivienda] es sin patio y sin nada, y todo como de plástico, de afuera y de adentro... Todo el sacrificio que hicimos ahí... ahora le van a pasar la topadora por encima. (Esther, delegada de la Villa 21-24, 2011)

La visión ecuánime de la delegada nos proporciona una clave de interpretación: las rudimentarias políticas de traslado solo son percibidas como satisfactorias cuando sus destinatarios pertenecen a aquello que Castel (2010) denomina la última zona de exclusión. Como subraya Esther, la expectativa de mudarse -o, en el caso de los ya mudados, el grado de satisfacción residencial- depende de sus capitales acumulados: si para los que alquilan o viven "muy a la orillita del río, en malas condiciones, es como mudarse a Barrio Norte", ${ }^{6}$ los que "tienen su casita" hace más de veinte años $-\mathrm{y}$, en algunos casos, con mejor calidad constructiva que las viviendas nuevas- no se quieren ir. Es a partir de su propia trayectoria que los afectados apreciarán como deseable o indeseable la perspectiva de la mudanza. ${ }^{7}$

Off the record, un profesional actuante en uno de los organismos ejecutores coincide con el diagnóstico perentorio de la delegada:

Los mudás a zonas de suelo residual con poco equipamiento comunitario y menor aprovisionamiento [...]. El centro de salud [cercano al nuevo complejo habitacional] no da abasto y eso no está contemplado... ¿Eso es derecho a la ciudad? Dejaste a la gente en el metro 36 en las mismas condiciones. [...] La provisión de vivienda es solo un medio para un fin, que es la liberación del camino de sirga.

Para combatir estas y otras arbitrariedades, los afectados de la Villa 21-24 organizaron una asamblea de delegados que se reúne semanalmente. En ella participan uno o dos delegados de cada sector de la sirga y representantes de instituciones sintonizadas con sus padecimientos, como la directora de la Fundación Temas, un abogado de la Defensoría General de la Ciudad, el sacerdote de la iglesia barrial y el Asesor Tutelar de Menores. Los profesionales que participaron en las reuniones de los delegados mediaron eficazmente en las aguas turbulentas de las diferencias entre estos últimos, con el objeto de que ellas no afectaran las posteriores negociaciones en las mesas de trabajo ${ }^{8}$ con el Instituto de Vivienda.

4 La "gente del meandro" hace alusión a los habitantes de la zona más precaria del camino de sirga de la Villa 21-24.

5 Las Cañitas es una zona exclusiva de Buenos Aires, ubicada en las calles adyacentes a la cancha de polo del barrio de Palermo, que se caracteriza por su oferta gastronómica de excelencia.

6 Se trata de una de las zonas más exclusivas de la ciudad de Buenos Aires. En un sentido coincidente, dos profesionales de un organismo público interviniente en la relocalización me comentaban durante una conversación informal: "los que están peor van a ir adonde los manden... ¡se hubieran ido a Marte si los hubieran mandado!”.

7 Como señala Benhabib (en Cowan, 2010, p. 84), la cultura no solo está conformada por una red de narraciones y actividades, sino por el horizonte formado por las posturas evaluatorias de tales narraciones y actividades, en las cuales los acontecimientos son clasificados como buenos o malos, sagrados o profanos, puros o impuros.

8 Se trata de un novedoso espacio de interlocución con el Instituto de Vivienda que comenzó a implementarse en 2011. Allí participaron no solo los representantes del Instituto de Vivienda, 
A tono con la postura de los organismos defensores, los vecinos de la villa reclamaron -ya sea en las mesas de trabajo o en las marchas realizadas durante 2012 y 2013 a las oficinas del Instituto de Vivienda- que se relocalizara en forma prioritaria a las familias con mayor sufrimiento ambiental. El discurso de los vecinos subsumía una variedad de jergas que habían escuchado, aquí y allá, en su interacción con profanos y expertos.

Reclamamos que sean las casi 400 familias que viven en el Meandro de Brian, ${ }^{9}$ la zona más afectada, las primeras en ser relocalizadas. Un 30\% de los chicos que viven en el Meandro de Brian están enfermos con plomo en sangre, tienen problemas respiratorios, dermatológicos, incluso hay personas con cáncer, y estamos luchando para que salgan ellos primero, y esperamos que el Ivc [el Instituto de Vivienda] nos escuche. (Declaraciones de una delegada del camino de sirga de la Villa 21-24, en una protesta y corte de calle frente al Instituto de Vivienda. Télam, 4 de julio de 2013)

La incorporación de nuevas categorías por parte de los afectados-como la presencia de plomo en sangre o el sufrimiento ambiental- no solo acorta las distancias lingüísticas entre un discurso científico y un saber popular, sino también la distancia social. ${ }^{10}$ Incluso antes de los estudios de toxicología, los vecinos saben los riesgos que corren porque se los dice su propio cuerpo. ${ }^{11} \mathrm{La}$ enfermedad se transforma entonces en un elemento a la vez perturbador y revelador (Fassin, 2004, p. 294).

El dolor y el sufrimiento no solo configuran una experiencia intransferible de estas personas, sino que operan en la positividad de esa experiencia para crear comunidades morales: el sufrimiento individual es transformado, bajo ciertas circunstancias, para fines de una acción colectiva (Das \& Scheper-Hughes en Pita, 2010, pp. 27 y 196). El sufrimiento aquí manifestado es la punta del iceberg de una injusticia al mismo tiempo social, espacial y ambiental.

Por otra parte, la narrativa del sufrimiento corporal de los afectados empalma con el discurso de los derechos humanos, el déficit de vivienda y la construcción de una agenda en torno a sectores populares urbanos que padecen. Uno de los reclamos de los afectados se vincula con recuperar el método tradicional en la construcción de las nuevas viviendas, tal como fue defendido por un delegado durante un evento público:

Seguimos batallando... vamos a exigir viviendas tradicionales con ladrillos, hierros, columnas y sobre todo losa. [...] queremos tener una vida digna dentro de nuestra pobreza. [...] ) Nosotros merecemos que [las viviendas] sean dignas, permanentes, definitivas, como lo dice la manda judicial. Porque ellos quieren liberar

ACUMAR y los delegados de los distintos sectores de la sirga de la Villa 21-24, sino también algunos representantes de ONG y organismos defensores. Cfr. Carman, 2017.

9 El Meandro de Brian es la zona más vulnerable de los márgenes de la Villa 21-24. Allí habitan familias cartoneras en casillas rodeadas de basura, con cloacas a cielo abierto y surcadas por un tren de carga que de vez en cuando se cobra una vida.

10 Esta idea se inspira en el trabajo de Boltanski (1975) sobre los usos sociales del cuerpo.

11 Como sostiene Wynne (en Beck, 2009, p. 37), el conocimiento público del riesgo muchas veces no es un conocimiento profesional sino popular, y como tal carece de reconocimiento social. 
el camino de sirga... ¡Nosotros no les pedimos que nos construyan una vivienda!

(Declaraciones durante la presentación de la Revista de la Defensa Pública de la

Ciudad de Buenos Aires, 2015)

Como sostiene Cowan (2010, pp. 67 y 71), el eventual acceso a nuevos derechos produce nuevas relaciones sociales. Este hecho es indisociable de algo fácilmente comprobable en los últimos veinte años: los sectores populares aluden cada vez más explícitamente a sus derechos. En otro trabajo (Carman, 2011), he argumentado de qué modo los habitantes de una villa con riesgo de expulsión hilvanan creativamente la jerga ambiental, judicial y médica en su lucha por la permanencia.

\section{El riesgo y la réplica al infortunio}

Las políticas de desplazamiento -aun aquellas más arbitrarias que ni siquiera garantizan la relocalización- se legitiman en el bien supremo de la vida de esos pobladores y la supuesta interrupción del padecimiento de esos cuerpos; unos cuerpos que deben ser separados de su actual hábitat para ser rehabilitados.

Este discurso altruista del poder local no representa ninguna novedad: en el caso de la Villa Rodrigo Bueno estudiado en una etnografía previa (Carman, 2011, pp. 37-103), el Poder Ejecutivo porteńo invocaba el valor supremo de la vida como derecho humano básico que pretendía ser garantizado expulsando a los habitantes de allí, pero sin procurarles a cambio un sitio donde vivir. Una insignificante suma de dinero se convertía en la única compensación para derrumbar sus casas por la fuerza y echarlos, bajo la solemne declaración de estar velando por su seguridad ante posibles inundaciones o derrumbes y de garantizar, en suma, su derecho humano básico a la vida.

Este derecho a la vida se traduce, en la coyuntura de la cuenca Matanza-Riachuelo, en el derecho a habitar un ambiente sano. Pero lo cierto es que si bien la argumentación ambiental ha sido la más trajinada por parte de los organismos ejecutores, no ha habido un sistemático seguimiento de salud de los afectados de la cuenca, ya sea que estén relocalizados o no. ${ }^{12}$ En otras palabras, la política de relocalización sigue su curso sin que necesariamente se avance en detectar científicamente el sufrimiento ambiental de los involucrados. Contar con información más exhaustiva hubiera sido beneficioso, entre otras cosas, para reexaminar en cada caso el límite genérico de 35 metros fijado por el juez.

Recién en los últimos años se han comenzado a realizar los primeros estudios sobre las condiciones de salud de los afectados en dos espacios paradigmáticos de la sirga: la Villa 21-24 e Inflamable. El estudio socioambiental realizado por ACUMAR a casi mil nińos de la Villa 21-24 indica que el 25\% tiene altos niveles de plomo en sangre. Los coordinadores del monitoreo aclaran, sin embargo, que los resultados

12 Los únicos antecedentes relevantes son los estudios de JiCA I y II (Japan International Cooperation Agency) en Villa Inflamable, que no son demostrativos del resto de la cuenca, por su condición singular de estar ubicada al lado de un Polo Petroquímico. El segundo estudio de JiCA, presentado en 2003, demostró el sufrimiento ambiental del 50\% de los niños de esta villa, expresado en sus altos niveles de plomo en sangre. 
obtenidos en villas alejadas de esta cuenca resultan similares, por lo que la proximidad al Riachuelo no es el único factor determinante sobre la salud.

El trabajo de campo nos provee innumerables relatos de sufrimiento ambiental en niños y adultos de villas capitalinas próximas al Riachuelo: niños con parasitosis; cuadros infecciosos; problemas hematológicos, dermatológicos o respiratorios crónicos.

Hay un montón de contaminantes por estar cerca del río: irritantes de mucosa; el olor a huevo podrido, que es ácido sulfúrico; miles de problemas en la piel, en los bronquios; los efluentes de curtiembres que son cancerígenos... las lechugas de nuestra huerta estaban cargadas de plomo. Hay contaminación aérea del Riachuelo por metales que se depositan como rocío en las comidas. (Directora de oNG de la Villa 21-24)

En ambas orillas del Riachuelo, la falta de acceso seguro al agua potable y la contaminación de suelos por la actividad industrial ponen en riesgo la salud de la población, especialmente respecto de las enfermedades "hídricas". ${ }^{13}$

Por otra parte, el gobierno nacional de Cristina Kirchner trabajó en pos de lograr un registro único de historias clínicas. El Sistema Nacional de Vigilancia Epidemiológica elaboró un protocolo de treinta enfermedades para el caso de la cuenca (leptopirosis, catarro, diarrea, etcétera) que deben informarse, y a partir del cual se arma una semaforización que sirve para mostrar eventuales picos de tales enfermedades. Esta semaforización se mantuvo estable en la cuenca durante años. Asimismo, el Ministerio de Salud de la Nación financió unidades sanitarias fijas en lugares críticos de la cuenca, que se sumaron a las unidades sanitarias móviles que recorren la cuenca con servicios de clínica, oftalmología, ginecología y odontología.

Esta novedosa preocupación por el sufrimiento ambiental por parte del Estado Nacional convive con una contradictoria e intermitente presencia del Estado local en las villas, que pone en práctica una codificación diferenciada de riesgos similares (Douglas, 1996, p. 143). ¿A qué nos referimos con esto? Por un lado, el Gobierno de la Ciudad invoca una serie de riesgos -el sufrimiento ambiental, el derecho supremo a la vida o peligros de derrumbe- cuando quiere expulsar un asentamiento. Al mismo tiempo, el poder local omite e ignora riesgos fehacientes con los que conviven los sectores populares, como el pésimo estado de las instalaciones eléctricas o el tren de carga que cruza por entre las casas, en el caso de la Villa 21-24; aquello que Auyero y Berti (2013) denominan la dimensión material del abandono estatal.

\section{El suplemento de alma}

$\mathrm{Al}$ sufrimiento ambiental se suma un padecimiento emocional presente en las anteriores relocalizaciones, y que se replica en el caso de la Villa 21-24: incertidumbres generadas por amenazas, rumores, atribución de culpa a las propias víctimas, informaciones erráticas o ausencia de información por parte del Ejecutivo porteńo. En la

13 Como aborda Merlinsky (2011, p. 20), la falta de servicio sanitario se vincula con la transmisión de nueve enfermedades consideradas hídricas: fiebres entéricas, amibiasis, hepatitis infecciosa, cólera, poliomielitis, arsenismo, osteoporosis fluórica, fluorosis dental y metahemoglobinemia. 
búsqueda de revertir ese maltrato, las defensorías visibilizan este padecimiento emocional de los afectados y lo inscriben en sus alegatos junto al padecimiento físico, logrando así un suplemento de alma (Fassin, 2003, pp. 59-60) en sus peticiones.

Cruzando el Riachuelo encontramos experiencias similares que exhiben esta tensión entre sufrimiento ambiental y merecimiento habitacional, como el caso de las precarias viviendas de Villa Corina construidas, literalmente, sobre el muro del cementerio de Avellaneda. Frente a la constatación de que líquidos cadavéricos traspasaban el muro hacia el interior de las viviendas, sus habitantes fueron beneficiados con el acceso a un plan de viviendas. Estos habitantes, conocidos como los de la tira del cementerio, fueron casi los únicos de la villa en obtenerlo (Jauri \& Olejarczyk, 2013). Otros vecinos, que también tuvieron el privilegio de "entrar" en una operatoria de vivienda, fueron aquellos que habían "aguantado" unos años a la vera de un afluente del Riachuelo -vale decir, en el peor sitio imaginable- con la esperanza de ser los primeros en ser relocalizados.

La gente persiste allí no para quedar mejor encuadrada en el delito de usurpación -circunstancia que los atemoriza, entre otras cosas, por las dificultades que puede traerle a la hora de conseguir un empleo formal-, sino porque se trata de una lección que han aprendido en sus constantes interacciones con dependencias del Estado: el tiempo de permanencia constituye uno de los ejes claves a partir de los cuales se constituye hegemónicamente el "merecimiento" o no a un plan de vivienda. A mayor tiempo de permanencia (aun con enfermedades vinculadas a la humedad, o con sufrimiento ambiental), mayores posibilidades de ser contemplados por el Estado en algún programa habitacional. Si los pobres están, desde una perspectiva dominante, fuera del tiempo -en el sentido de no ser realmente nuestros contemporáneos ${ }^{14}-$, ellos pueden esperar.

Con un Estado local anestesiado frente a los padecimientos populares, y en el contexto más amplio de una sociedad que tolera sin demasiado escándalo ciertas pérdidas de vidas humanas por frío, inanición o enfermedades curables, es preciso ser el más sufriente para acelerar los tiempos de acceso a los derechos.

\section{La lógica equivalencial de los seres sufrientes}

El aluvión de críticas vertido por los afectados y los organismos defensores sobre la ineficaz gestión del Instituto de Vivienda durante el funcionamiento de las mesas de trabajo en 2011 no hizo sino reforzar una estructura jerárquica que minó la participación de los vecinos y los castigó por su descaro en socavar la autoridad. La réplica del Instituto de Vivienda no consistió en revertir su inoperancia -ya sea en la recepción de las demandas o en la agilidad para resolverlas-, sino en obstaculizar las mesas de trabajo para luego, por decisión unilateral, suspenderlas. Con la brusca interrupción de las mesas de trabajo, los vecinos ya relocalizados o por relocalizar perdieron un relevante espacio de diálogo para hacer escuchar sus demandas y evitar la reiteración de "errores" y omisiones en la entrega de las casas. 
Solo a fines de 2012, el Instituto de Vivienda contrató personal más capacitado y reanudó la participación de los actores "vedados" en las mesas de trabajo, a partir de una suma de reclamos -tales como las marchas de los afectados ${ }^{15}$ y las reiteradas quejas de los organismos defensores- que volvían insostenible tal esquema de obediencia.

El nuevo equipo territorial del Instituto de Vivienda intentó implementar una línea de intervención más participativa con la población afectada, orientada principalmente a garantizar el derecho a la información de los vecinos. Venciendo la previsible sospecha inicial de muchas de las familias, las jóvenes profesionales del nuevo equipo en terreno colaboraron con los vecinos en la conformación de asambleas y en la elección de sus representantes; intercedieron -sin mucho éxito- en la resolución de problemas técnicos o deficiencias que presentaban las casas; presionaron a las autoridades del Instituto de Vivienda y de la Dirección de Reciclado para construir establos para los caballos de los carreros y fundamentaron por qué resultaba importante que esas familias se mudaran en forma conjunta para sostener su actividad económica.

Si bien la intervención de este nuevo equipo resultó en muchos aspectos infructífera - pues la mala calidad constructiva y otros tantos problemas estructurales permanecen incólumes-, se crearon condiciones de interlocución que incluyeron respeto por las aspiraciones de los afectados y por los modos en que ellos iban delineando su organización. Si el lector me permite una digresión, recuerdo que los vecinos de la Villa 21-24 solían relatarme no solo condiciones de padecimiento objetivo -la pobreza estructural o el sufrimiento ambiental-, sino aspectos que ellos consideraban indignantes de su relación con empleados y funcionarios del Instituto de Vivienda: los ultimátums de mudanza; sus "reproches" por haberse construido una casa a pocos metros del Riachuelo. Una compleja trayectoria vital era reducida, bajo esa mirada, a un desacierto y una elección inmoral.

Aquello que otorgó un sentido a la actividad de las nuevas trabajadoras sociales -la presencia regular en el barrio y el apoyo a la organización consorcial de los afectados- supuso para sus superiores, en cambio, una mera nota de color. A los ojos de estos últimos, el trabajo pre y posrelocalización de las empleadas "de a pie" fue visto como superfluo, excepto cuando el barrio se transformaba súbitamente en un hervidero de conflictos - a causa de una grave deficiencia estructural en las viviendas, por ejemplo-y sus intervenciones eran justificadas como un instrumento pacificador.

El trabajo procesual con los vecinos por parte de las trabajadoras de base fue traducido por los funcionarios como una sobreimplicación de sus empleadas. ¿Para qué "malgastar" tanta energía en la vida ordinaria de los afectados? El núcleo duro de los funcionarios de ese Instituto estima que las trabajadoras sociales actuantes en el territorio son "zurdas, de armas tomar y están siempre del lado del vecino"; y que estos últimos "se aprovechan" de sus nuevas viviendas para abrir un negocio o bien para venderlas y "volver a la villa"; que no "merecen" acceder a una nueva

15 En 2013, los afectados de la Villa 21-24 se movilizaron hasta el Instituto de Vivienda y cortaron una calle céntrica en reclamo por una relocalización justa. También aprovecharon visitas de otros funcionarios, como el jefe de Gabinete nacional o el juez de Morón, para denostar la ineficiente gestión del Instituto de Vivienda en cuanto a su mudanza. 
casa si tuvieron un paso por el sistema carcelario; y que sus reclamos son desproporcionados frente al "regalo" que supone un nuevo hogar. "Esta es la herencia del asistencialismo -exclama indignado uno de ellos-; la gente pide y pide y pide. ¡Tendrían que estar entre cuatro chapas, y ahora tienen agua corriente y se quejan!”.

Las intervenciones de este equipo de trabajo territorial nos remiten a un interesante trabajo de Lipsky (1996), que analiza la influencia de los empleados de base (street-level bureaucrats) sobre la elaboración de las políticas públicas a partir de dos vías: la toma de decisiones que afectan a los ciudadanos y la incorporación de su estilo individual de actuación al comportamiento del organismo. ¿Cuáles son las discrepancias que se producen entre las políticas planeadas y las políticas reales, y de qué modo esa grieta puede fortalecer la relativa autonomía del trabajador social en su vínculo con la comunidad? La falta de identificación de los empleados de base con los objetivos o el modus operandi impulsado por sus superiores les permite eventualmente proponer, como señala Lipsky (1996), contramedidas que dan cuenta del abismo de apreciaciones entre unos y otros respecto de las poblaciones afectadas.

$\mathrm{Al}$ interior del Instituto de Vivienda, diferentes percepciones sobre los sectores populares fundamentan un abanico de prácticas contradictorias. ¿Se trata de mera beneficencia, de un programa más o menos autoritario que hay que ejecutar con una participación residual de los beneficiarios, o bien de un conjunto de derechos que han de ser garantizados y debatidos con los futuros relocalizados?

Aun con modestos avances en términos de horizontalidad y participación, lo cierto es que las problemáticas más acuciantes de las relocalizaciones jamás fueron revertidas. Pese a los resultados del estudio de ACUMAR, el gobierno porteño continuó sin atender la problemática de los niños con plomo en sangre. Asimismo, los relocalizados de la Villa Luján continuaban sin gas y sin cloacas luego de tres ańos de mudados, y las viviendas de otros complejos -como San Francisco y Padre Mugica- persistían con ausencia de centros de salud comunitarios, así como serias deficiencias o falta de mantenimiento.

Yo me tuve que mudar acá porque soy un caso prioritario, pero mis hijos están al lado de la caballeriza. [...] No podemos seguir viviendo así. Tenemos los departamentos a la miseria, con un montón de problemas. Todo es berreta... ¿Por qué nos mandan a un lugar así? (Vecina relocalizada al complejo Padre Mugica, 2013)

La pérdida de redes y de equipamiento comunitario representa un problema adicional para los vecinos de todas las edades:

Antes allá [en la Villa 21-24] estaba el comedor y [los chicos] podían ir a buscar ahí. Pero acá [el complejo Padre Mugica] no puede faltar la leche. Todo lo que me entra tiene que ser para leche... ¡me chupa todo! [...] Los chicos están agobiados... ahora se quieren volver para ir a la Casa del Niño, el apoyo escolar [de la Villa 21-24]... ¡acá no hay nada! (Vecina relocalizada al complejo Padre Mugica, 2013) 


\section{Consideraciones finales}

Los sectores populares que habitan en las proximidades del cauce contaminado tienen un estatus ambivalente: se los considera víctimas -en tanto portadores de un sufrimiento ambiental- y a veces una suerte de estorbo pasivo, expropiado de agencia. En los cuatro ańos posteriores al fallo Mendoza, el entonces juez a cargo de la ejecución de la sentencia interpretó la presencia de estos moradores populares ribereños como un obstáculo para la parquización y el trazado del camino de sirga. $\mathrm{Al}$ igual que aquellos objetos que impedían la liberación del camino -basurales, casas, escombros-, estas personas debían ser removidas con toda la celeridad que fuese posible para dar cumplimiento al fallo. Los primeros afectados de la ciudad de Buenos Aires no tuvieron más opción que la de seguir habitando un único territorio: el de su propio cuerpo. ${ }^{16}$ Cuando diversos organismos defensores procuraron frenar la arbitrariedad de esas expulsiones, el juez desoyó sus reclamos e impidió su inscripción en la causa.

Si bien casi todos los actores implicados en el proceso de relocalización retoman la bandera del sufrimiento ambiental, esta simbiosis argumentativa no los conduce a los mismos resultados. En efecto, el hecho de que utilicen una narrativa ambiental con cierto grado de parentesco no significa que las prácticas o políticas que cada bloque de actores pone en juego tengan un contenido asimilable: en unos, se trata de lograr una efectiva consolidación de derechos; en otros, alcanza con entregar una "vivienda para pobres", con mínimos estándares de habitabilidad.

Inicialmente, la designación hegemónica de los afectados en tanto tales operó menos como el acceso a una mayor afiliación que como una politica de reconocimiento cultural: las condiciones materiales de vida no se vieron mejoradas al contar con la novedosa etiqueta de ser víctimas ambientales.

El hecho de ser beneficiarios de derechos ambientales les confería a los primeros afectados una humanidad más bien abstracta, enunciativa. La cobertura de sus derechos no quedó garantizada por un criterio universalista. El derecho a un ambiente sano -o más precisamente, un cierto modo de traducir ese derecho a una praxisno trajo aparejadas las condiciones necesarias para continuar su vida en el nuevo emplazamiento -en aquellos casos en que lo hubo- y vulneró, en muchos casos, el derecho a la salud, la educación o la movilidad de sus destinatarios.

Esta teleología del nombre o fetiche de la nominalización (Bhabha, 2013, p. 122) refiere más a una suerte de identidad cultural -ser damnificado de un mal ambiente; ser un afectado- que a un efectivo mejoramiento de su hábitat o estructura de oportunidades. La retórica humanitario-ambiental bien puede estancarse en una mera demagogia hacia una minoría oprimida.

Si, como señala Heffes (2013, p. 15), “aquellas personas que se encuentran en una jerarquía social [...] privilegiada tienen el poder de transformar los objetos en duraderos o transitorios y asegurarse $[. .$.$] que su propio patrimonio pertenezca a la$

Este comentario retoma una reflexión de Segato (2007, p. 73): “...cuando no resta más nada, nos reducimos y remitimos al territorio de nuestro cuerpo como primero y último bastión de la identidad". 
esfera de la durabilidad", del mismo modo se confina a los sectores populares a una permanente transitoriedad a partir de políticas tales como los hoteles-pensión, los paradores y hogares de tránsito, o bien las viviendas con graves vicios constructivos.

Así como las personas son concebidas en su puro presente, algo similar sucede con la política que les es destinada, en tanto no suponen un seguimiento de las vidas cuyo destino fue alterado. Como vimos especialmente en la primera parte del trabajo, solo las condiciones a priori fueron evaluadas como productoras de sufrimiento -vivir a orillas del río contaminado, en una vivienda precaria sin servicios- y no las que provocó el propio poder local durante el proceso de ejecución de la sentencia. ${ }^{17}$ Veamos al respecto la lúcida reflexión de una profesional interviniente en los procesos de relocalización:

Todos vamos generando ese discurso de que todo el mundo está enfermo para que se convenza, para que se quiera ir... hasta con los adictos. ¿¿De qué le va a servir mudarse al adicto? [...] Hasta los prioritarios de la Villa 21-24 tienen ese discurso de "estoy enfermo". [...] El objetivo es la liberación del camino de sirga, no hay un objetivo de política habitacional en serio. Podría ser violento el proceso, pero contra la enfermedad no se puede discutir. [...] Lo mismo pasa con mis jefes: cualquier cosa que [los afectados] les piden, ellos te dicen que van a un lugar donde van a estar mejor, que no está contaminado... lo usan para justificar que no se comprometen. Con eso alcanza y eso justifica cualquier otra carencia.

Las expulsiones violentas de los primeros afectados, o bien las más disuasivas relocalizaciones como la de la Villa 21-24, comprenden diversos tipos de bio-lógicas o bio-legitimidades: aquellas formas en que los seres sufrientes o los cuerpos enfermos son diferencialmente reconocidos cuando son sometidos a los exámenes de la política (Fassin, 2004, p. 310). Nuestro trabajo etnográfico volvió inteligible esa gradación de humanidades por parte de los ejecutores de las políticas: cuáles sufrientes son sancionados como merecedores o no de una vivienda, fuera del territorio que es necesario parquizar.

Para los organismos defensores y los afectados de la Villa 21-24, por el contrario, la relocalización se vincula con un deber de justicia: una demanda de derechos universal que apela a la razón y se desliga del arbitrio o "buena voluntad" de quien ha de ejecutar esa política.

Los argumentos que esgrimen defensores y afectados respecto de los riesgos en la vida biológica de estos últimos -como la presencia de plomo en sangre-se fusionan con la preocupación por la vida social: sostener las redes de afiliación en su nuevo domicilio, por ejemplo. La alusión al cuerpo biológico de los afectados opera, en este caso, como un primer paso en la lucha por la dignidad.

La conciencia ambiental de los afectados deriva de la coyuntura que les toca vivir y del intercambio con un vasto espectro de actores; bajo otras circunstancias, probablemente ni siquiera hubiera emergido. Dar cuenta de las condiciones que habilitan el desarrollo de una perspectiva ambiental nos permite comprender este

17 El sufrimiento en el espacio público, como seńala Fassin (2010, p. 64) se banaliza: se trata de modos de gobierno que se esfuerzan para volver vivibles vidas que continúan siendo precarias, ocultando las causas sociales de su condición. 
ambientalismo popular -al igual que muchos otros- como parte de un proceso cultural más amplio (Milton, 1993, p. 11).

Los seres sufrientes o sus portavoces narran los padecimientos en términos materiales -el porcentaje de plomo en sangre de los niños- o en términos espirituales: temor, desazón o incertidumbre en los afectados. Ambas categorizaciones no son, por cierto, excluyentes. Lo que se intenta es bosquejar un rostro social -una visibilidad y una reparación- a ese cuerpo dañado.

En diálogo con la apropiación judicial y burocrática del sufrimiento (Das, 2008), los afectados oponen sus versiones personales de la dolencia. Los propios términos de amparado, prioritario o afectado resumen las anomalías, discapacidades o padecimientos ahora retraducidos por los profanos: alcanza con deletrear esas palabras mágicas para conjurar ese universo experto. La marca distintiva de esos cuerpos afectados permite demostrar la pertenencia a una misma comunidad moral.

En tanto las comunidades morales -y los sujetos que las componen- no se encuentran constituidos de antemano (Butler 2010, p. 54), resulta fundamental analizar sus devenires y transformaciones para comprender las dimensiones del sufrimiento ambiental. Una comunidad moral se nos revela cuando en las demandas diversas de un grupo -que comparte un habitus de clase y ciertas estructuras simbólicasopera una lógica equivalencial: se produce la unidad dentro de la heterogeneidad en actores distintos, aunque situados del mismo lado de la frontera antagónica (Laclau 2009 , pp. 300 y 307). En toda comunidad moral se instituyen fronteras de inclusión y de exclusión cuyos efectos, visibles o inadvertidos, solo lograremos ponderar a partir de una sumersión profunda con nuestros interlocutores del campo.

\section{Agradecimientos}

Esta investigación se desarrolló en el marco del proyecto UвACYT 20020130200097; del PICT-2013-1887 de la ANPCyt y en el marco del proyecto CONTESTED_CITIEs, con financiación de la línea people-IRses del Séptimo Programa Marco de la Comisión Europea (Contrato PIRSES-GA-2012-318944).

\section{Referencias bibliográficas}

Abramovich, V. (2007). Acceso a la justicia y nuevas formas de participación en la esfera política. Revista Estudios Socio-Jurídicos, 9, 9-33. https://bit.ly/2Fm6qHF

Auyero, J. \& Berti, M. F. (2013). La violencia en los márgenes. Buenos Aires: Katz.

Beck, U. (2009). La sociedad del riesgo global. Madrid: Siglo Xxi editores.

Bhabha, H. K. (2013). Nuevas minorias, nuevos derechos. Buenos Aires: Siglo xxI editores.

Boltanski, L. (1975). Los usos sociales del cuerpo. Buenos Aires: Periferia.

Bourdieu, P. (1985). ¿Qué significa hablar? Madrid: Akal.

Butler, J. (2010). Marcos de guerra. Las vidas lloradas. Buenos Aires: Paidós.

Carman, M. (2011). Las trampas de la naturaleza. Medio ambiente y segregación en Buenos Aires. Buenos Aires: Fondo de Cultura Económica-Clacso. 
Carman, M. (2017). Las fronteras de lo humano. Cuando la vida humana pierde valor y la vida animal se dignifica. Buenos Aires: Siglo XxI editores.

Castel, R. (2010). El ascenso de las incertidumbres. Buenos Aires: Fondo de Cultura Económica.

Chellillo, M., López, M. J., Royo, L. Sagasti I. \& Territoriale, A. (2014). El “cómo”. Propuesta de un modelo de defensa para la causa Riachuelo. Revista institucional de la Defensa Pública de la Ciudad Autónoma de Buenos Aires (G), 41-60.

Cowan, J. K. (2010). Cultura y derechos después de Culture and Rights. Revista de Antropología Social, 19, 67-101. https://bit.ly/2FsbvOy

Das, V. (2008). Sufrimientos, teodiceas, prácticas disciplinarias y apropiaciones. En V. Das \& F. Ortega (eds.), Sujetos del dolor, agentes de dignidad (pp. 437-458). Bogotá: Universidad Nacional de Colombia.

Douglas, M. (1996) [1985]. La aceptabilidad del riesgo según las ciencias sociales. Barcelona: Paidós.

Fabian, J. (1983). Time and the other. How Anthropology makes its object. Nueva York: Columbia University Press.

Fassin, D. (2003). Gobernar por los cuerpos, políticas de reconocimiento hacia los pobres y los inmigrantes en Francia. Cuadernos de Antropología Social, 17(1), 49-78. https://bit. ly/2ROyEvU

Fassin, D. (2004). Entre las políticas de lo viviente y las políticas de la vida. Revista Colombiana de Antropología, 40, 283-318. https://bit.ly/2qFRrhD

Fassin, D. (2010). La raison humanitaire. París: Seuil / Gallimard.

Habermas, J. (1999). La inclusión del otro. Estudios de teoría política. Barcelona: Paidós.

Heffes, G. (2013). Políticas de la destrucción / Poéticas de la preservación. Apuntes para una lectura (eco)crítica del medio ambiente en América Latina. Rosario, Argentina: Beatriz Viterbo.

Jauri, N. \& Olejarczyk, R. (2013). La jerarquización de la demanda. Un análisis comparativo de procesos de adjudicación de viviendas. Revista INVI, 28(77), 167-190. https://bit. ly/2RKtiSC

Laclau, E. (2009). La razón populista. Buenos Aires: Fondo de Cultura Económica.

Lipsky, M. (1996). Los empleados de base en la elaboración de políticas públicas. En Q. Brugué \& J. Subirats (eds.), Lecturas de gestión pública (pp. 279-298). Madrid: Ministerio de Administraciones Públicas.

Merlinsky, G. (2011). El plan integral de saneamiento ambiental de la cuenca MatanzaRiachuelo: desafíos para la gestión integrada del agua en la Región Metropolitana de Buenos Aires. En F. Isuani (ed.), Política pública y gestión del agua: aportes para un debate necesario (pp. 320-340). Buenos Aires: Universidad Nacional de General Sarmiento (UNGS) / Prometeo.

Merlinsky, G. (2013). Politica, derechos y justicia ambiental. El conflicto del Riachuelo. Buenos Aires: Fondo de Cultura Económica.

Milton, K. (1993). Introduction. En K. Milton (ed.), Environmentalism. The view from anthropology (pp. 1-17). Londres: Routledge.

Pita, M. V. (2010). Formas de morir y formas de vivir. El activismo contra la violencia policial. Buenos Aires: Del Puerto / Centro de Estudios Legales y Sociales (CELs).

Segato, R. (2007). La Nación y sus Otros: raza, etnicidad y diversidad religiosa en tiempos de Políticas de la Identidad. Buenos Aires: Prometeo Libros. 
Silvestri, G. (2003). El color del río. Historia cultural del paisaje del Riachuelo. Buenos Aires: Universidad Nacional de Quilmes / Prometeo.

Svampa, M. (2012). Cambio de época. Movimientos sociales y poder politico. Buenos Aires: Siglo XxI editores. 